\title{
RESEARCH
}

Open Access

\section{The assessment of risk factors for long-term survival outcome in ypN0 patients with rectal cancer after neoadjuvant therapy and radical anterior resection}

Marcin Zeman ${ }^{1 *}$ D, Marek Czarnecki ${ }^{1}$, Ewa Chmielik², Adam Idasiak³ ${ }^{3}$ Władysław Skałba ${ }^{1}$, Mirosław Strączyński ${ }^{1}$, Piotr J. Paul ${ }^{2,4}$ and Agnieszka Czarniecka ${ }^{1}$

\begin{abstract}
Background: The main negative prognostic factors in patients with rectal cancer after radical treatment include regional lymph node involvement, lymphovascular invasion, and perineural invasion. However, some patients still develop cancer recurrence despite the absence of the above risk factors.

The aim of the study was to assess clinicopathological factors influencing long-term oncologic outcomes in ypNOMO rectal cancer patients after neoadjuvant therapy and radical anterior resection.

Methods: A retrospective survival analysis was performed on a group of 195 patients. We assessed clinicopathological factors which included tumor regression grade, number of lymph nodes in the specimen, Charlson comorbidity index (CCI), and colorectal anastomotic leakage (AL).

Results: In the univariate analysis, $\mathrm{AL}$ and $\mathrm{CCl}>3$ had a significant negative impact on disease-free survival (DFS), disease-specific survival (DSS), and overall survival (OS). After the division of ALs into early and late ALs, it was found that only patients with late ALs had a significantly worse survival. The multivariate Cox regression analysis showed that $\mathrm{CCl}>3$ was a significant adverse risk factor for DFS (HR 5.78, 95\% Cl 2.15-15.51, $p<0.001$ ), DSS (HR 7.25, 95\% $\mathrm{Cl} 2.25-23.39, p<0.001)$, and OS (HR 3.9,95\% Cl 1.72-8.85, $p=0.001$ ). Similarly, late ALs had a significant negative impact on the risk of DFS (HR 5.05, 95\% Cl 1.97-12.93, $p<0.001$ ), DSS (HR 10.84, 95\% Cl 3.44-34.18, $p<0.001$ ), and OS (HR 4.3, 95\% Cl 1.94-9.53, $p<0.001)$.
\end{abstract}

Conclusions: Late AL and CCl $>3$ are the factors that may have an impact on long-term oncologic outcomes. The impact of lymph node yield on understaging was not demonstrated.

Keywords: Stage migration, Rectal neoplasms, Lymph node yield, Charlson comorbidity index, Late anastomotic leak, Anterior rectal resection

\footnotetext{
* Correspondence: mzeman@wp.pl

${ }^{1}$ The Oncologic and Reconstructive Surgery Clinic, Maria Sklodowska-Curie National Research Institute of Oncology, Gliwice Branch, Wybrzeze Armii Krajowej 15, 44-100 Gliwice, Poland

Full list of author information is available at the end of the article
}

C C The Author(s). 2021 Open Access This article is licensed under a Creative Commons Attribution 4.0 International License, which permits use, sharing, adaptation, distribution and reproduction in any medium or format, as long as you give appropriate credit to the original author(s) and the source, provide a link to the Creative Commons licence, and indicate if changes were made. The images or other third party material in this article are included in the article's Creative Commons licence, unless indicated otherwise in a credit line to the material. If material is not included in the article's Creative Commons licence and your intended use is not permitted by statutory regulation or exceeds the permitted use, you will need to obtain permission directly from the copyright holder. To view a copy of this licence, visit http://creativecommons.org/licenses/by/4.0/. The Creative Commons Public Domain Dedication waiver (http://creativecommons.org/publicdomain/zero/1.0/) applies to the data made available in this article, unless otherwise stated in a credit line to the data. 


\section{Background}

Long-term treatment results of rectal cancer patients after the introduction of combined treatment regimens and the techniques of total mesorectal excision have significantly improved [1]. After neoadjuvant therapy and radical surgery, negative prognostic factors include regional lymph node involvement and a number of histopathological factors related to the potential for tumor invasiveness, such as lymphovascular invasion (LVI), perineural invasion (PNI), poor differentiation, or the mucinous component of the tumor [2, 3]. However, even some ypNOM0 patients with no additional histopathological risk factors have a relapse. Several studies showed a negative impact of colorectal anastomotic leakage (AL) on long-term survival after anterior rectal resection (AR) [4, 5]. However, such findings were not confirmed in all studies [6]. Additionally, the minimum number of lymph node yield (LNY) that could allow to avoid understaging in ypNO patients has not been established either. Research found either a negative impact $[7,8]$ or no impact $[9,10]$ of low LNY on longterm oncologic outcomes. The influence of preoperative radiotherapy on the reduction in the number of resected lymph nodes was also demonstrated [11]. Some studies found that low LNY was associated with a good response to neoadjuvant therapy [12]. Few studies suggested that apart from the effect associated with increased mortality due to comorbidities, their direct impact on the course of the neoplastic disease was possible. However, the mechanism of this interaction has not been fully understood yet [13].

The aim of the study was to assess the selected clinicopathological factors influencing long-term oncologic outcomes in ypNOM0 rectal cancer patients after neoadjuvant therapy and radical AR in the group of patients with a good prognosis without major histological risk factors.

\section{Methods}

\section{Patients}

Between 2008 and 2016, 328 radical (R0) ARs were performed at the National Research Institute of Oncology in Gliwice, Poland, in rectal cancer patients after neoadjuvant therapy without synchronous distant metastases. Metastases that occurred within 3 months after surgery were considered synchronous. Prior to treatment, all patients had been staged T3N0 or T1-3N+. The process of selecting the low-risk study group is given in the flowchart (see Additional file 1). Finally, 195 patients (82 females, 113 males) without main risk factors were enrolled in a retrospective study. Patient characteristics are given in Table 1.

\section{Procedures}

All patients were given neoadjuvant therapy, i.e., radiotherapy (RT) or chemoradiotherapy (CRT). In the RT
Table 1 Patient characteristics

\begin{tabular}{|c|c|c|}
\hline & & $\mathbf{n}$ \\
\hline Sex & Females & $82(42.1 \%)$ \\
\hline Age & Mean (SD) & $64(10.03)$ \\
\hline BMI (kg/m2) & Mean (SD) & $26.21(4.03)$ \\
\hline \multirow[t]{3}{*}{$\mathrm{CCl}$} & 2 & $142(72.8 \%)$ \\
\hline & 3 & $42(21.6 \%)$ \\
\hline & $>3$ & $11(5.6 \%)$ \\
\hline \multirow[t]{2}{*}{ Clinical stage prior to treatment } & $\|$ & $58(29.7 \%)$ \\
\hline & III & $137(70.3 \%)$ \\
\hline \multirow[t]{2}{*}{ Neoadjuvant therapy } & RT & $127(65.1 \%)$ \\
\hline & CRT & $68(34.9 \%)$ \\
\hline Time RT-S $>=6$ weeks & Yes & $107(54.9 \%)$ \\
\hline \multirow[t]{3}{*}{ Distance from the anal verge $(\mathrm{cm})$} & $1-5$ & $57(29.2 \%)$ \\
\hline & $6-10$ & $93(47.7 \%)$ \\
\hline & $11-15$ & $45(23.1 \%)$ \\
\hline Loop ileostomy & Yes & $41(21 \%)$ \\
\hline \multirow[t]{3}{*}{$y G$} & 1 & $16(8.2 \%)$ \\
\hline & 2 & $111(57.2 \%)$ \\
\hline & $x$ & $67(34.5 \%)$ \\
\hline \multirow[t]{3}{*}{ урт } & 0 & $17(8.7 \%)$ \\
\hline & $1-2$ & $98(50.3 \%)$ \\
\hline & 3 & $80(41 \%)$ \\
\hline LNY & Mean (SD) & $12.16(6.01)$ \\
\hline \multirow[t]{3}{*}{ LNY groups } & $1-7$ & $45(23.1 \%)$ \\
\hline & $8-12$ & $72(36.9 \%)$ \\
\hline & $>12$ & $78(40 \%)$ \\
\hline Width of the distal margin $(\mathrm{cm})$ & Mean (SD) & $2.13(1.41)$ \\
\hline \multirow[t]{2}{*}{ TRG } & $0-1$ & $91(46.7 \%)$ \\
\hline & $2-3$ & $104(53.3 \%)$ \\
\hline \multirow[t]{3}{*}{ Anastomotic leakage } & No & $158(81 \%)$ \\
\hline & Early & $22(11.3 \%)$ \\
\hline & Late & $15(7.7 \%)$ \\
\hline Adjuvant chemotherapy & Yes & $16(8.2 \%)$ \\
\hline
\end{tabular}

$S D$ standard deviation, $B M I$ body mass index, $C C I$ Charlson comorbidity index, $G$ tumor grade, $R T$ radiotherapy, CRT chemoradiotherapy, Time RT-S time from completion of radiotherapy to surgery, $L N Y$ lymph node yield, TRG tumor regression grade

group, the total dose was 25-42 Gy, while in the CRT group it was 42-54 Gy combined with 1 or 2 cycles of 5fluorouracil-based chemotherapy. Tumor regression grade (TRG) was based on the assessment of the degree of fibrosis compared to the residual tumor tissue and ranged from 0 to 3 , i.e., 0 (complete response), 1 (< $10 \%$ residual tumor), 2 (10-50\%), and 3 (> 50\%). The procedure was performed by laparotomy using the total mesorectal excision technique. End-to-end intestinal anastomosis was performed with a circular stapler. According to the 
International Study Group of Rectal Cancer (ISREC), AL was defined as a defect of the intestinal wall at the anastomotic site, which resulted in a communication between the intra- and extraluminal compartments and/or the presence of a pelvic abscess near the anastomotic site [14]. All ALs were confirmed radiologically. A CT scan with rectal contrast was performed when symptoms suggestive of possible AL were present [15]. AL diagnosed within 30 days postoperatively was considered early, whereas AL diagnosed after 30 days postoperatively was regarded as late. The severity of comorbidities was assessed based on the original Charlson comorbidity index (CCI) [16] (see Additional file 2).

\section{Variables}

The factors which were analyzed in terms of their impact on survival included sex, age, body mass index (BMI), body surface area (BSA), CCI, clinical stage prior to treatment, type of neoadjuvant therapy (RT vs CRT), time from RT to surgery, rectal tumor location, loop ileostomy (LI), tumor grade (G), ypT, LNY, TRG, width of the distal margin, length of the resected intestine, occurrence of AL with the division into early and late ALs, and post-surgical adjuvant chemotherapy.

\section{Statistical methods}

The survival analysis was performed using the KaplanMeier method with the log-rank test. The multivariate analysis was performed using the Cox regression (proportional hazard model). The chi ${ }^{2}$ test was used to assess differences in event rates between the groups. All calculations were made using the statistical package $R$ version 3.6.0.

\section{Results}

AL was postoperatively found in 37/195 (19\%) cases, including 22/37 (59.5\%) early and 15/37 (40.5\%) late ALs. Four patients with early ALs (4/22; $18.2 \%)$ and 2 patients with late ALs $(2 / 15 ; 13.3 \%)$ underwent loop ileostomy (LI) at the time of primary surgery (chi ${ }^{2}$ test, $p=0.7$ ). The time from surgery to the diagnosis of early and late ALs was 3-27 days (mean 7.7 days) and 36-650 days (mean 137 days), respectively. The severity of ALs according to the ISREC is given in Table 2. The mean LNY was 12.15 (range 1-37, SD 6.01) and the median was 11 (IQR 8-16). The mean follow-up of the study group was 69 months.

Table 2 Grading of ALs according to the International Study Group of Rectal Cancer

\begin{tabular}{lll}
\hline & Grade A & Grade C \\
\hline Early ALs $(n=22)$ & $2(9.1 \%)$ & $20(90.9 \%)$ \\
Late ALs $(n=15)$ & $4(26.7 \%)$ & $11(73.3 \%)$ \\
\hline
\end{tabular}

AL Anastomotic leakage
In the univariate analysis of survival, the occurrence of AL had a significant impact on DFS, DSS, and OS, as shown by the log-rank test. After the division of ALs into early and late ALs, it was found that only patients with late ALs had a significantly worse prognosis. The probability of survival depending on the occurrence of $\mathrm{AL}$ is given in Fig. 1. Patients with $\mathrm{CCI} \leq 3$ had a significantly better prognosis compared to patients with CCI > 3 in terms of DFS, DSS, and OS. The probability of survival depending on CCI is given in Fig. 2. Table 3 lists the 3- and 5-year survival probabilities depending on the above factors. No relationship was found between survival and other parameters, including LNY. The probability of survival depending on LNY is given in Fig. 3.

The results of the univariate and multivariate Cox regression analyses are presented in Table 4. In the multivariate analysis, CCI $>3$ was a significant risk factor for DFS (HR 5.78, 95\% CI 2.15-15.51, $p<0.001$ ), DSS (HR 7.25, 95\% CI 2.25-23.39, $p<0.001$ ), and OS (HR 3.9, 95\% CI 1.72-8.85, $p=0.001$ ). Similarly, the occurrence of late AL had a significant negative impact on the risk of DFS (HR 5.05, 95\% CI 1.97-12.93, $p<$ 0.001 ), DSS (HR 10.84, 95\% CI 3.44-34.18, $p<0.001$ ), and OS (HR 4.3, 95\% CI 1.94-9.53, $p<0.001$ ). No significant influence of early AL or other factors on longterm survival was found.

\section{Discussion}

Despite the influence of ALs on long-term oncologic outcomes $[4,5,17]$, some reports did not confirm such a relationship $[6,18,19]$. There are several hypotheses in the literature which explain the possible mechanisms of AL-induced cancer relapse [20]. It was shown that during the resection procedure, exfoliated malignant cells which are present in the lumen of the colon have the potential to be implanted into the surrounding tissues. In the case of AL, these cells can penetrate beyond the lumen of the intestine and initiate secondary tumor foci [21]. Another hypothesis highlights the role of acute phase factors and inflammatory mediators in tumor progression and metastasis. In vitro studies found that the peritoneal fluid collected from patients with ALs or from patients with other inflammatory processes in the abdominal cavity resulted in an increase in migration and invasion of cancer cell lines [22]. Additionally, both circulating cancer cells and immune cells show the tendency to migrate to inflammatory sites, thus enhancing the cascade of angiogenesis and proliferation. Impossibility to administer adjuvant chemotherapy or deferral of such therapy is a possible indirect mechanism of the impact of AL on survival. However, this mechanism seems less likely in this case, given the characteristics of the low-risk group and the lack of impact of adjuvant chemotherapy in our analysis. We demonstrated that 


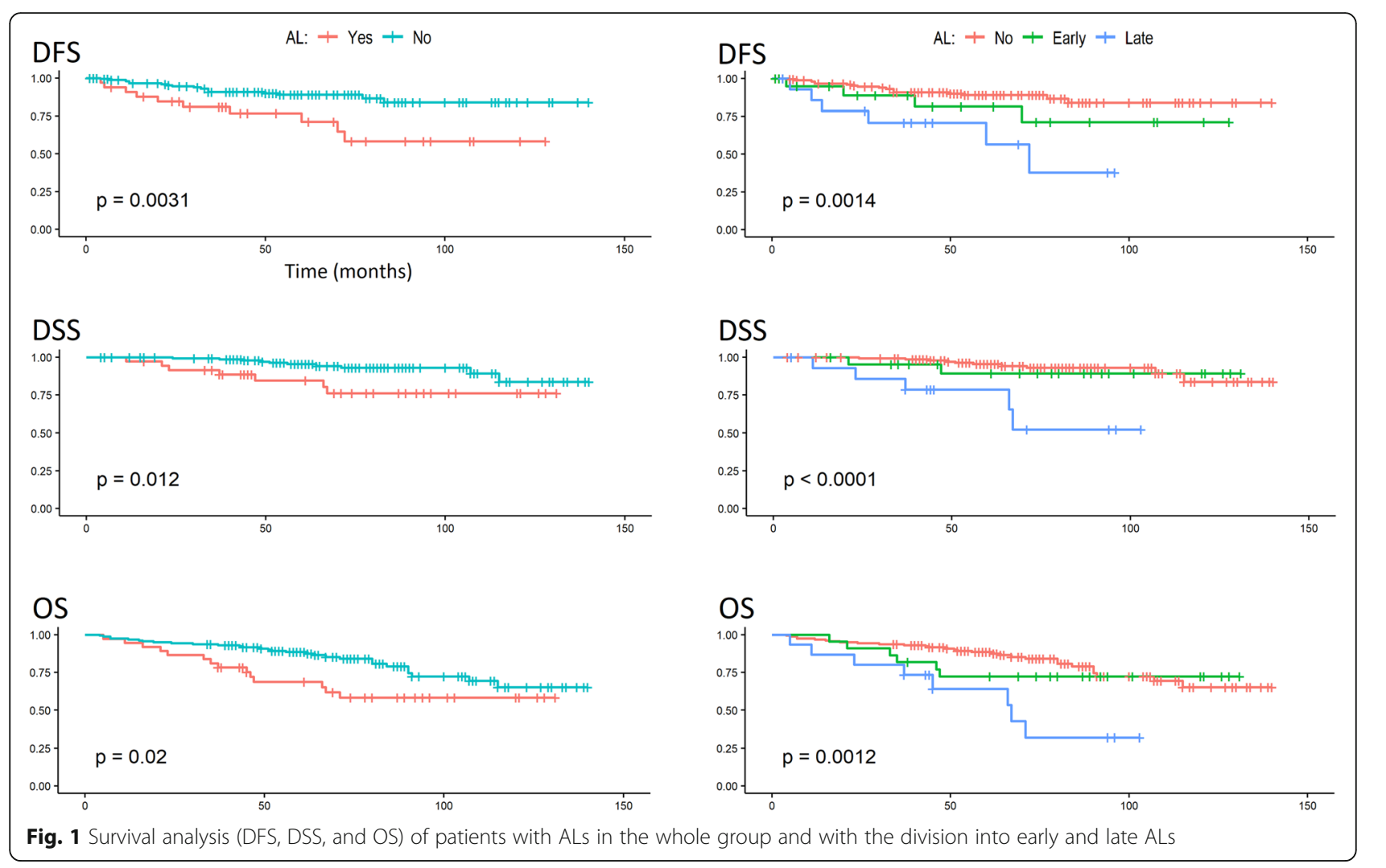

only late ALs had an adverse effect on survival. Late ALs are an underestimated clinical problem in rectal cancer surgery. More than $50 \%$ of ALs may occur after hospital discharge, whereas $25-40 \%$ may occur after 30 days following surgery $[23,24]$. Definitions of late AL are different, depending on the authors. The common criterion is a period of over 30 days after surgery. However, a period of over 90 days and a less precise determination of AL after hospital discharge were also reported [23]. In accordance with the criterion we adopted, late ALs accounted for $40.5 \%$ of all ALs in our material. Late AL is more prevalent in patients with LI, which can be explained by a delay in the diagnosis of AL [25]. It was not confirmed in our material. However, this may be due to the relatively low rate of LI in our patients. The etiopathogenesis of late AL has not yet been elucidated. According to some reports, patient-dependent factors such as the severity of comorbidities or past RT, which may adversely affect the healing process, play a role in late ALs, as opposed to early ALs, where risk factors are mainly those that influence the course of surgery $[24,26]$ It was found that late ALs were more asymptomatic compared to early ALs. They were more prevalent in the form of fistulas and did not often require radical surgical intervention and became chronic over time. Chronic presacral sinus formation was more commonly found in late ALs (even in $65 \%$ of cases) [27].
To the best of our knowledge, there are no reports in the literature that could explain the adverse effect of late ALs with a simultaneous lack of impact of early ALs on survival. Considering that the course of late ALs is usually chronic, it is possible that the duration of influence of the pathogenetic factor can play an important role. However, this is only our hypothesis. More research is needed on the pathogenesis of late ALs in terms of their impact on survival.

We demonstrated a negative effect of CCI $>3$ on DFS, DSS, and OS. The influence of comorbidities on the survival of cancer patients may result from several mechanisms. Comorbidities increase the risk of death during the follow-up for reasons other than cancer. They also limit the possibility of optimal treatment (e.g., adjuvant systemic treatment) and may also directly affect tumor progression. While the first two causes are evident and have an established impact on OS, the mechanism of the direct influence of comorbidities is still unclear, although the problem has been raised for a long time [28, 29]. Diabetes mellitus is the only disease in which a direct impact on DFS was confirmed in locally advanced and disseminated colorectal cancer, regardless of systemic treatment. A direct interaction between diabetes and the progression of colorectal cancer is associated with hyperinsulinemia, an increase in insulin-like growth factor, hyperglycemia, and inflammation [30]. Comorbidities 


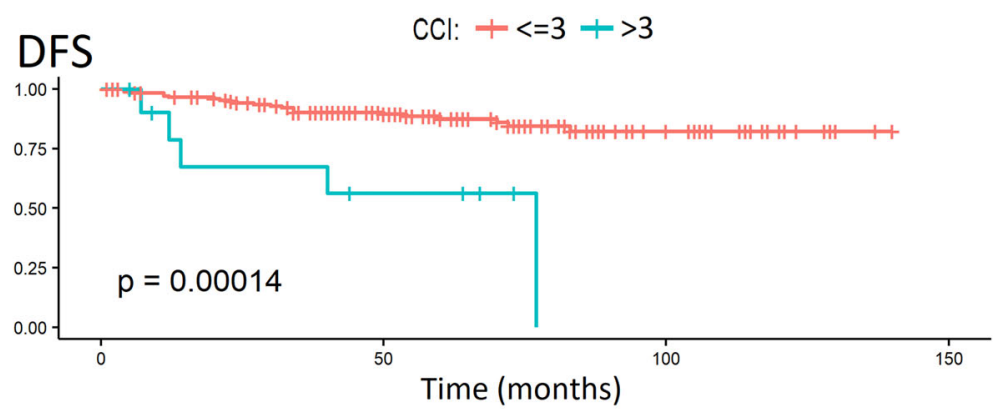

DSS
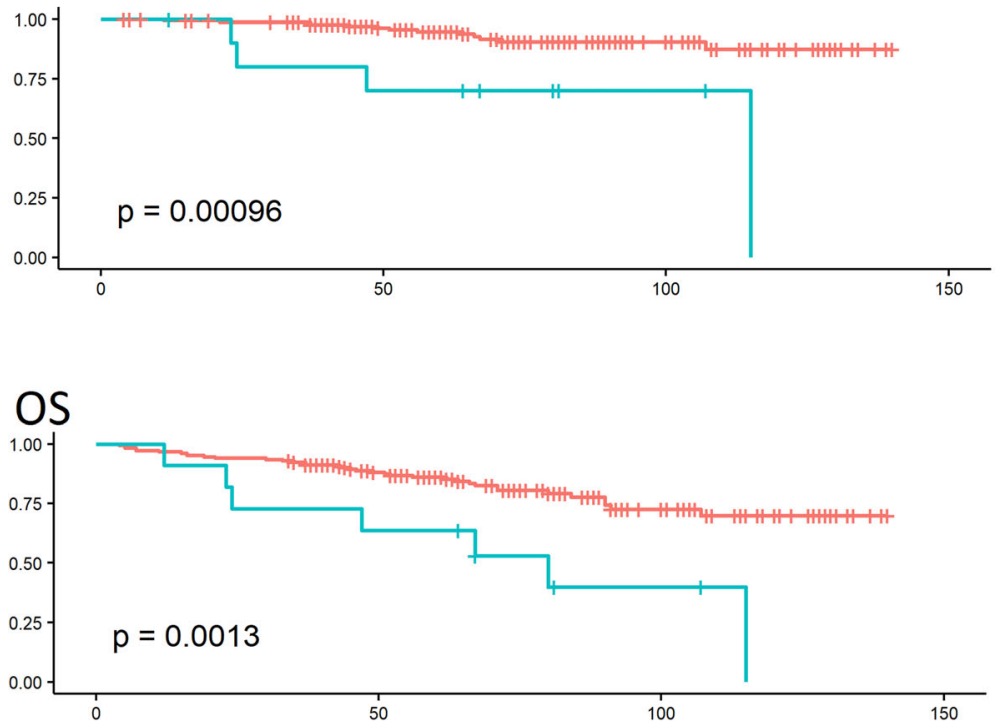

Fig. 2 Survival analysis (DFS, DSS, and OS) depending on CCI ( $\leq 3$ vs $>3$ )

may result in the exclusion of patients from adjuvant therapy. In our analysis, most patients did not require standard adjuvant therapy. Only $8.2 \%$ of patients underwent such therapy. However, we demonstrated the impact of CCI on DFS without the simultaneous influence of adjuvant chemotherapy on the probability of survival. Therefore, it seems that in ypN0 patients, the influence of CCI on DFS can be the result of the direct influence of comorbidities on the course of cancer disease.
However, the mechanism of this interaction remains unknown. Baretti et al. showed that the presence of comorbidities assessed by CCI had a significant negative impact on DFS and OS in stage II/III colorectal cancer patients. However, they did not perform the analysis of individual stages or locations [11]. The influence of CCI on DFS and OS in patients with stages I-III colorectal cancer and different tumor location was demonstrated by Yamano et al. who did not find the influence of CCI

Table 3 Three- and 5-year survival probabilities depending on the parameters significant in the univariate analysis

\begin{tabular}{|c|c|c|c|c|c|c|}
\hline & \multicolumn{2}{|l|}{ DFS } & \multicolumn{2}{|l|}{ DSS } & \multicolumn{2}{|l|}{ OS } \\
\hline & 3 years $\%$ & 5 years $\%$ & 3 years $\%$ & 5 years $\%$ & 3 years $\%$ & 5 years $\%$ \\
\hline Total study group & 89.0 & 85.7 & 97.9 & 93.4 & 91.3 & 84.8 \\
\hline No AL & 90.8 & 88.9 & 99.3 & 95.3 & 93.7 & 88.4 \\
\hline$A L$ & 80.9 & 71.2 & 91.5 & 84.3 & 81.1 & 68.6 \\
\hline Early AL & 88.8 & 81.4 & 95.2 & 89.3 & 81.8 & 72.2 \\
\hline Late AL & 70.7 & 56.6 & 85.7 & 77.9 & 80.0 & 63.6 \\
\hline $\mathrm{CCl} \leq 3$ & 90.2 & 87.4 & 98.3 & 94.7 & 92.4 & 86.0 \\
\hline $\mathrm{CCl}>3$ & 67.5 & 56.2 & 80.0 & 70.0 & 72.7 & 63.6 \\
\hline
\end{tabular}

DFS disease-free survival, DSS disease-specific survival, OS overall survival, $A L$ anastomotic leakage, CCI Charlson comorbidity index 

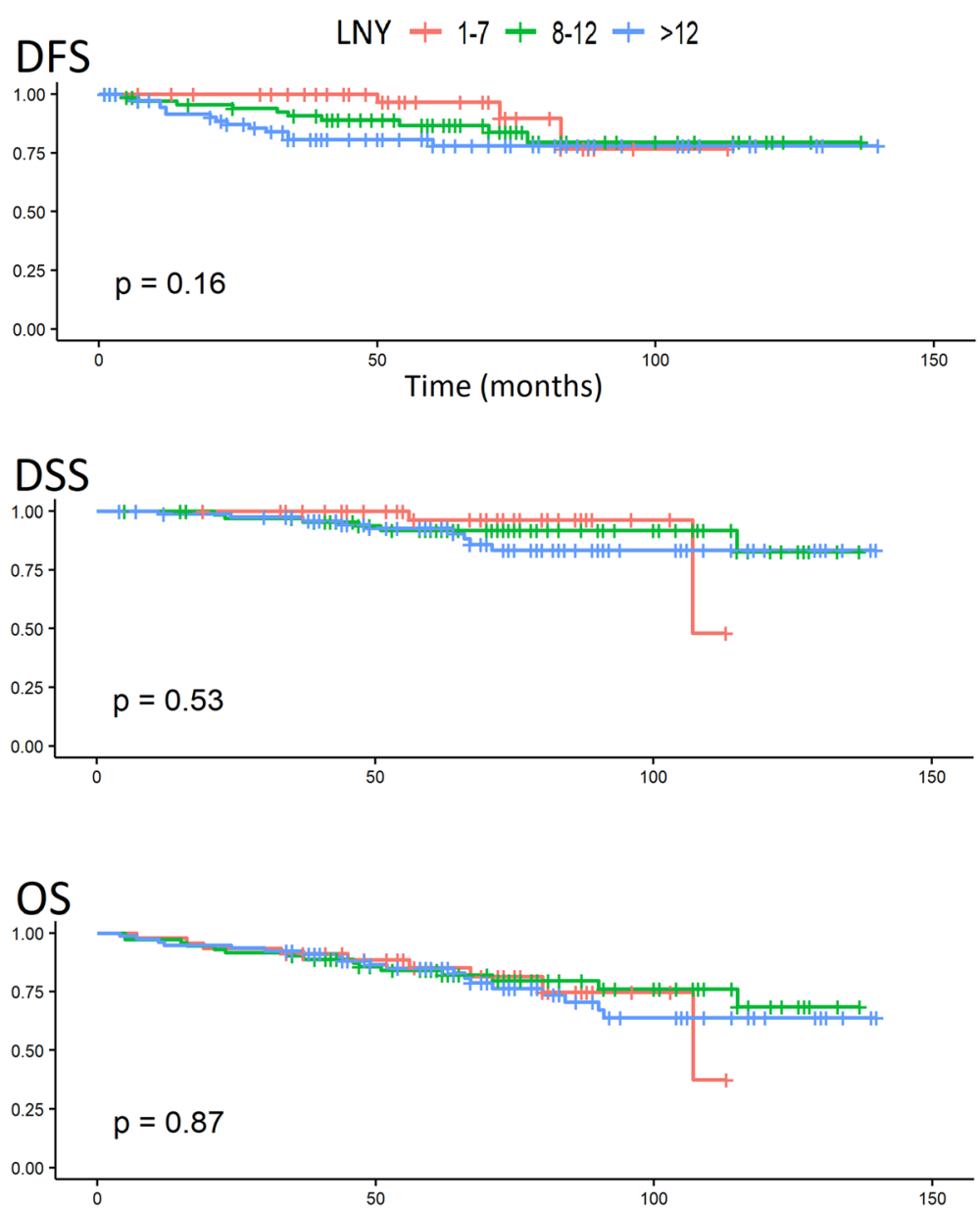

Fig. 3 Survival analysis (DFS, DSS, and OS) of patients depending on LNY

on DFS in patients with stage II [31]. The mechanism by which CCI affects DSS can be complex and can be related to a direct influence of comorbidities on tumor progression. Additionally, it should be noted that in patients with active cancer disease, death may also occur due to diseases other than cancer. However, it can be reported as cancer-related death in medical records, which may distort the results of the analyses.

It has been shown that preoperative nodal understaging in rectal cancer patients may be related to approximately $15 \%$ of patients compared to histological assessment. However, neither the effect of the above finding nor the impact of clinical nodal staging on long-term outcomes was shown $[32,33]$. We did not find such an impact, although our analysis was conducted on a heterogeneous group of patients (cT3N0, cT1-3N+). Additionally, we did not demonstrate the prognostic influence of LNY. Studies confirmed the effects of ionizing radiation on lymph nodes, including stromal atrophy and fibrosis, as well as lymphocyte count reduction [34, 35]. Preoperative radiotherapy was shown to reduce the total number of removed lymph nodes [7, 12]. Of note, studies found the reduction in the number of lymph nodes due to the response to neoadjuvant therapy associated with the response of the immune system [36]. Studies on colon cancer patients found that despite the tendency to increase the number of removed nodes, the percentage of patients with metastatic lymph nodes did not increase [37, 38]. It was also shown that fat clearance increased the median number of retrieved lymph nodes in ypN0 rectal cancer patients from 12 to 19.5 compared to the conventional fixation method. However, it did not affect the long-term outcomes [39]. Thus, technical factors (both surgical and histological) seem to be of secondary importance in terms of understaging. Despite the above, attempts are made to establish the minimum number of lymph nodes below which a risk of understaging is observed and to determine a group of patients who might benefit from adjuvant treatment due to low LNY. The results of the studies are contradictory. It should be noted that most analyses reporting the cut-off point below which the understaging is found in ypN0 patients were based on single-center studies with a low $(\leq 7)$ 
Table 4 Results of univariate and multivariate Cox regression analyses

\begin{tabular}{|c|c|c|c|c|c|c|c|c|c|}
\hline & & \multicolumn{4}{|c|}{ Univariate } & \multicolumn{4}{|c|}{ Multivariate } \\
\hline & & $\overline{\mathrm{HR}}$ & $\mathrm{Cl} 2.5 \%$ & Cl $97.5 \%$ & $p$ & $\overline{\mathrm{HR}}$ & Cl $2.5 \%$ & $\mathrm{Cl} 97.5 \%$ & $p$ \\
\hline \multirow[t]{22}{*}{ DFS } & $\mathrm{CCl} \leq 3$ & Ref. & & & & & & & \\
\hline & $\mathrm{CCl}>3$ & 5.438 & 2.043 & 14.48 & $<0.001$ & 5.779 & 2.153 & 15.51 & $<0.001$ \\
\hline & Female & Ref. & & & & & & & \\
\hline & Male & 2.19 & 0.9255 & 5.184 & 0.0744 & & & & \\
\hline & PRETR ST ॥ & Ref. & & & & & & & \\
\hline & PRETR ST III & 0.6896 & 0.3156 & 1.506 & 0.3512 & & & & \\
\hline & $\begin{array}{l}\text { Dist av } \\
1-5 \mathrm{~cm}\end{array}$ & Ref. & & & & & & & \\
\hline & $6-10 \mathrm{~cm}$ & 0.6141 & 0.2494 & 1.512 & 0.2889 & & & & \\
\hline & $11-15 \mathrm{~cm}$ & 1.269 & 0.4858 & 3.313 & 0.6269 & & & & \\
\hline & урт0 & Ref. & & & & & & & \\
\hline & ypT1-2 & 1.888 & 0.2451 & 14.55 & 0.5417 & & & & \\
\hline & урт3 & 3.031 & 0.3978 & 23.1 & 0.2845 & & & & \\
\hline & LNY 1-7 & Ref. & & & & & & & \\
\hline & LNY 8-12 & 2.106 & 0.5791 & 7.66 & 0.2581 & & & & \\
\hline & $L N Y>12$ & 3.106 & 0.8916 & 10.82 & 0.0751 & & & & \\
\hline & No AL & Ref. & & & & & & & \\
\hline & $A L$ & 3.066 & 1.403 & 6.702 & 0.005 & & & & \\
\hline & No AL & Ref. & & & & & & & \\
\hline & Early AL & 2.001 & 0.6725 & 5.953 & 0.2125 & 1.96 & 0.6587 & 5.831 & 0.2265 \\
\hline & Late AL & 4.753 & 1.87 & 12.08 & 0.0011 & 5.051 & 1.974 & 12.93 & $<0.001$ \\
\hline & No adj $C T$ & Ref. & & & & & & & \\
\hline & Adj $C T$ & 0.695 & 0.1632 & 2.959 & 0.6225 & & & & \\
\hline \multirow[t]{20}{*}{ DSS } & $C C l \leq 3$ & Ref. & & & & & & & \\
\hline & $\mathrm{CCl}>3$ & 5.39 & 1.754 & 16.56 & 0.0033 & 7.252 & 2.249 & 23.39 & $<0.001$ \\
\hline & Female & Ref. & & & & & & & \\
\hline & Male & 1.543 & 0.54 & 4.41 & 0.418 & & & & \\
\hline & PRETR ST ॥ & Ref. & & & & & & & \\
\hline & PRETR ST III & 0.643 & 0.2443 & 1.692 & 0.3711 & & & & \\
\hline & $\begin{array}{l}\text { Dist av } \\
1-5 \mathrm{~cm}\end{array}$ & Ref. & & & & & & & \\
\hline & $6-10 \mathrm{~cm}$ & 0.5699 & 0.1834 & 1.771 & 0.3309 & & & & \\
\hline & $11-15 \mathrm{~cm}$ & 1.458 & 0.4378 & 4.855 & 0.5392 & & & & \\
\hline & урт0 & Ref. & & & & & & & \\
\hline & урТ1-2 & 0.7613 & 0.0883 & 6.565 & 0.804 & & & & \\
\hline & урт3 & 2.153 & 0.2754 & 16.83 & 0.4648 & & & & \\
\hline & LNY 1-7 & Ref. & & & & & & & \\
\hline & LNY 8-12 & 1.605 & 0.3207 & 8.033 & 0.5648 & & & & \\
\hline & LNY > 12 & 2.267 & 0.4854 & 10.59 & 0.2979 & & & & \\
\hline & No AL & Ref. & & & & & & & \\
\hline & $A L$ & 3.218 & 1.222 & 8.476 & 0.018 & & & & \\
\hline & No AL & Ref. & & & & & & & \\
\hline & Early AL & 1.245 & 0.2705 & 5.73 & 0.7785 & 1.543 & 0.3303 & 7.21 & 0.5812 \\
\hline & Late AL & 8.519 & 2.825 & 25.69 & $<0.001$ & 10.84 & 3.435 & 34.18 & $<0.001$ \\
\hline
\end{tabular}


Table 4 Results of univariate and multivariate Cox regression analyses (Continued)

\begin{tabular}{|c|c|c|c|c|c|c|c|c|c|}
\hline & & Univari & & & & Multiv & & & \\
\hline & & $\mathrm{HR}$ & Cl $2.5 \%$ & $\mathrm{Cl} 97.5 \%$ & $p$ & $\mathrm{HR}$ & $\mathrm{Cl} 2.5 \%$ & Cl $97.5 \%$ & $p$ \\
\hline & No adj CT & Ref. & & & & & & & \\
\hline & Adj $C T$ & 0.4898 & 0.0642 & 3.735 & 0.4911 & & & & \\
\hline OS & $\mathrm{CCl} \leq 3$ & Ref. & & & & & & & \\
\hline & $\mathrm{CCl}>3$ & 3.494 & 1.553 & 7.859 & 0.0025 & 3.899 & 1.718 & 8.85 & 0.0011 \\
\hline & Female & Ref. & & & & & & & \\
\hline & Male & 0.984 & 0.5321 & 1.82 & 0.9591 & & & & \\
\hline & PRETR ST ॥ & Ref. & & & & & & & \\
\hline & PRETR ST III & 0.6993 & 0.3791 & 1.29 & 0.2522 & & & & \\
\hline & Dist av $1-5 \mathrm{~cm}$ & Ref. & & & & & & & \\
\hline & $6-10 \mathrm{~cm}$ & 0.5456 & 0.281 & 1.06 & 0.0736 & & & & \\
\hline & $11-15 \mathrm{~cm}$ & 0.7257 & 0.3136 & 1.679 & 0.4538 & & & & \\
\hline & урт0 & Ref. & & & & & & & \\
\hline & урT1-2 & 1.258 & 0.2893 & 5.466 & 0.7598 & & & & \\
\hline & урT3 & 2.332 & 0.5488 & 9.905 & 0.2514 & & & & \\
\hline & LNY 1-7 & Ref. & & & & & & & \\
\hline & LNY 8-12 & 0.8853 & 0.3847 & 2.037 & 0.7746 & & & & \\
\hline & LNY > 12 & 1.064 & 0.4784 & 2.365 & 0.8798 & & & & \\
\hline & No AL & Ref. & & & & & & & \\
\hline & $\mathrm{AL}$ & 2.103 & 1.109 & 3.987 & 0.0227 & & & & \\
\hline & No AL & Ref. & & & & & & & \\
\hline & Early AL & 1.292 & 0.5347 & 3.123 & 0.5691 & 1.415 & 0.5835 & 3.431 & 0.4425 \\
\hline & Late AL & 3.943 & 1.792 & 8.677 & $<0.001$ & 4.298 & 1.939 & 9.526 & $<0.001$ \\
\hline & No adj CT & Ref. & & & & & & & \\
\hline & Adj $C T$ & 0.8261 & 0.2933 & 2.327 & 0.7177 & & & & \\
\hline
\end{tabular}

Bold values indicate statistical significance

DFS disease-free survival, DSS disease-specific survival, OS overall survival, $H R$ hazard ratio, $C l$ confidence interval, CCI Charlson comorbidity index, Dist av distance from the anal verge, PRETR ST pretreatment clinical stage, RT radiotherapy, LNY lymph node yield, $A L$ anastomotic leakage, Adj CT adjuvant chemotherapy

median number of removed lymph nodes in the entire group $[40,41]$ or were based on the data from the national multicenter registries $[8,9,42,43]$. Nevertheless, many studies indicated that LNY had no effect on understaging and thus on long-term survival in ypN0 patients, which is in line with our findings $[10,11,44-46]$. The results of our analysis may confirm the theory that LNY in ypNO patients should be considered in terms of the response to neoadjuvant therapy rather than as a determinant of the quality of surgical or histological procedures with no impact on long-term outcomes.

The analysis has limitations typical of retrospective and single-center analyses. CCI was assessed retrospectively based on medical record data. In addition, the strength of inference may be reduced by the fact that the study group is a predefined low-risk group.

\section{Conclusions}

Late AL and CCI > 3 are the factors that may influence long-term oncologic outcomes in ypNOM0 rectal cancer patients after neoadjuvant therapy and AR. No evidence of the impact of LNY on understaging was found.

\section{Abbreviations}

AL: Anastomotic leakage; AR: Anterior rectal resection; CCl: Charlson comorbidity index; CRT: Chemoradiotherapy; DFS: Disease-free survival; DSS: Disease-specific survival; G: Tumor grade; HR: Hazard ratio; ISRE C: International Study Group of Rectal Cancer; LI: Loop ileostomy; LNY: Lymph node yield; LVI: Lymphovascular invasion; OS: Overall survival; PNI: Perineural invasion; RT: Radiotherapy; SD: Standard deviation; TRG: Tumor regression grade

\section{Supplementary Information}

The online version contains supplementary material available at https://doi. org/10.1186/s12957-021-02262-x.

Additional file 1. Flowchart showing the formation of the study group 
Additional file $\mathbf{2}$. Charlson comorbidity index

\section{Acknowledgements}

We also acknowledge the translation assistance provided by Assistant Professor Arkadiusz Badziński, Ph.D., a medical translator and interpreter.

\section{Authors' contributions}

$M Z, M C$, and $A C$ participated in the study conception and design. $M Z, M C$, WS, MS, and PP participated in acquisition of the data. MZ, EC, and Al participated in data analysis and interpretation. MZ has drafted the manuscript. AC substantively revised the manuscript. All authors read and approved the final manuscript

\section{Funding}

The authors have no financial or material support to disclose.

\section{Availability of data and materials}

All data generated or analyzed during this study are included in this published article [and its supplementary information files].

\section{Declarations}

\section{Ethics approval and consent to participate}

This retrospective study involving human participants was in accordance with the ethical standards of the institutional research committee and with the 1964 Helsinki Declaration and its later amendments. The study was approved by the institutional ethics committee of National Research Institute of Oncology (KB/430-53/19). Due to the retrospective design of the study, the ethics committee confirmed that informed consent was not necessary from participants.

\section{Consent for publication}

Not applicable

\section{Competing interests}

The authors declare that they have no competing interests.

\section{Author details}

${ }^{1}$ The Oncologic and Reconstructive Surgery Clinic, Maria Sklodowska-Curie National Research Institute of Oncology, Gliwice Branch, Wybrzeze Armii Krajowej 15, 44-100 Gliwice, Poland. ${ }^{2}$ Tumor Pathology Department, Maria Sklodowska-Curie National Research Institute of Oncology, Gliwice Branch, Wybrzeze Armii Krajowej 15, 44-100 Gliwice, Poland. ${ }^{3}$ II Clinic of Radiotherapy and Chemotherapy, Maria Sklodowska-Curie National Research Institute of Oncology, Gliwice Branch, Wybrzeze Armii Krajowej 15, 44-100 Gliwice, Poland. ${ }^{4}$ Department of Pathology, Institute of Medical Sciences, University of Opole, Oleska 48, 45-052 Opole, Poland.

Received: 27 January 2021 Accepted: 11 May 2021

Published online: 21 May 2021

\section{References}

1. Coraglio MF, Eleta MA, Kujaruk MR, Oviedo JH, Roca EL, Masciangioli GA et al. Analysis of long-term oncological results of clinical versus pathological responses after neoadjuvant treatment in locally advanced rectal cancer. World J Surg Oncol. 2020 Nov 30;18(1):313. https://doi.org/10.1186/s12957020-02094-1.

2. Pagès F, Berger A, Camus M, Sanchez-Cabo F, Costes A, Molidor R, et al. Effector memory T cells, early metastasis and survival in colorectal cancer. N Engl J Med. 2005;353(25):2654-66. https://doi.org/10.1056/NEJMoa051424.

3. Van den Berg I, Van den Braak RRJ C, JLA W, JNM I, Buettner S. Actual survival after resection of primary colorectal cancer: results from a prospective multicenter study. World J Surg Oncol. 2021;19(1):96. https://doi. org/10.1186/s12957-021-02207-4

4. Hain E, Maggiori L, Manceau G, Mongin C, Prost À la Denise J, Panis Y. Oncological impact of anastomotic leakage after laparoscopic mesorectal excision. Br J Surg. 2017;104(3):288-95. https://doi.org/10.1002/bjs.10332.

5. Allaix ME, Rebecchi F, Famiglietti F, Arolfo S, Arezzo A, Morino M. Long-term oncologic outcomes following anastomotic leak after anterior resection for rectal cancer: does the leak severity matter? Surg Endosc. 2020;34(9):416676. https://doi.org/10.1007/s00464-019-07189-9.

6. Jang JH, Kim HC, Huh JW, Park YA, Cho YB, Yun SH, et al. Anastomotic leak does not impact oncologic outcomes after preoperative

chemoradiotherapy and resection for rectal cancer. Ann Surg. 2019;269(4): 678-85. https://doi.org/10.1097/SLA.0000000000002582.

7. Li X, Lu H, Xu K, Wang H, Liang X, Hu Z. Negative lymph node count is an independent prognostic factor for patients with rectal cancer who received preoperative radiotherapy. BMC Cancer. 2017;17(1):227. https://doi.org/10.11 86/s12885-017-3222-8

8. Li Q, Zhuo C, Liang L, Zheng H, Li D, Cai S. Lymph node count after preoperative radiotherapy is an independently prognostic factor for pathologically lymph node-negative patients with rectal cancer. Medicine. 2015;94(3):e395. https://doi.org/10.1097/MD.0000000000000395.

9. Wang $Y$, Zhou $M$, Yang J, Sun X, Zou W, Zhang Z, et al. Increased lymph node yield indicates improved survival in locally advanced rectal cancer treated with neoadjuvant chemoradiotherapy. Cancer Med. 2019;8(10): 4615-25. https://doi.org/10.1002/cam4.2372.

10. Klos CL, Shellito PC, Rattner DW, Hodin RA, Cusack JC, Bordeianou L, et al. The effect of neoadjuvant chemoradiation on the prognostic value of lymph nodes after rectal cancer surgery. Am J Surg. 2010;200(4):440-5. https://doi.org/10.1016/j.amjsurg.2010.03.013.

11. Ishihara S, Fukushima Y, Akahane T, Horiuchi A, Shimada R, Nakamura K, et al. Number of lymph nodes in rectal cancer is correlated with response to preoperative chemoradiotherapy but is not associated with patients survival. Hepatogastroenterology. 2014;61(132):1000-7.

12. Kim HJ, Jo JS, Lee SY, Kim CHm Kim YJ, Kim HR. Low lymph node retrieval after preoperative chemoradiation for rectal cancer is associated with improved prognosis in patients with a good tumor response. Ann Surg Oncol. 2015;22(6):2075-81. https://doi.org/10.1245/s10434-014-4235-z.

13. Baretti M, Rimassa L, Personeni N, Giordano L, Tronconi MC, Pressiani T, et al. Effect of comorbidities in stage I//II colorectal cancer patients treated with surgery and neoadjuvant/adjuvant chemotherapy: a single-center, observational study. Clin Colorectal Cancer. 2018;17(3):e489-98. https://doi. org/10.1016/j.clcc.2018.03.010.

14. Rahbari NN, Weitz J, Hohenberger W, Heald RJ, Moran B, Ulrich A, et al. Definition and grading of anastomotic leakage following anterior resection of the rectum: a proposal by the International Study Group of Rectal Cancer. Surgery. 2010;147(3):339-51. https://doi.org/10.1016/j. surg.2009.10.012.

15. Cirocchi R, Randolph J, Panata L, Verdelli AM, Mascagni D, Mingoli A, Zago M, Chiarugi M, Lancia M, Fedeli P, Davies J, Occhionorelli S. The tip of the iceberg of colorectal perforation from enema: a systematic review and meta-analysis. Tech Coloproctol. 2020;24(11):1109-1119. doi: https://doi.org/1 0.1007/s10151-020-02294-7. Epub 2020 Jul 14. PMID: 32666361.

16. Charlson ME, Pompei P, Ales KL, MacKenzie CR. A new method of classifying prognostic comorbidity in longitudinal studies: development and validation. J Chron Dis. 1987;40(5):373-83. https://doi.org/10.1016/0021-9681(87)90171-8.

17. Koedam TWA, Bootsma BT, Deijen CL, van de Brug T, Kazemier G, Cuesta MA, Fürst A, Lacy AM, Haglind E, Tuynman JB, Daams F, Bonjer HJ; COLOR COLOR II study group||. Oncological outcomes after anastomotic leakage after surgery for colon or rectal cancer: increased risk of local recurrence. Ann Surg. 2020. doi: https://doi.org/10.1097/SLA.0000000000003889. Epub ahead of print. PMID: 32224742.

18. Crippa J, Duchalais E, Machairas N, Merchea A, Kelley SR, Larson DW. Longterm oncological outcomes following anastomotic leak in rectal cancer surgery. Dis Colon Rectum. 2020;63(6):769-77. https://doi.org/10.1097/DCR. 0000000000001634

19. Espin E, Ciga MA, Pera M, Ortiz H. Oncological outcome following anastomotic leak in rectal surgery. Br J Surg. 2015;102(4):416-22. https://doi. org/10.1002/bjs.9748.

20. Gaines S, Shao C, Hyman M, Alverdy JC. Gut microbiome influences on anastomotic leak and recurrence rates following colorectal cancer surgery. Br J Surg. 2018;105(2):e131-41. https://doi.org/10.1002/bjs.10760.

21. Hasegawa J, Nishimura J, Yamamoto S, Yoshida Y, Iwase K, Kawano K, et al. Exfoliated malignant cells at the anastomosis site in colon cancer surgery: the impact of surgical bowel occlusion and intraluminal cleaning. Int J Colorectal Dis. 2011;26(7):875-80. https://doi.org/10.1007/s00384-011-1148-1.

22. Salvans S, Mayol X, Alonso S, Messeguer R, Pascual M, Mojal S, et al. Postoperative peritoneal infection enhances migration and invasion capacities of tumor cells in vitro: an insight into the association between 
anastomotic leak and recurrence after surgery for colorectal cancer. Ann Surg. 2014;260(5):939-43. https://doi.org/10.1097/SLA.0000000000000958.

23. Jutesten H, Draus J, Frey J, Neovius G, Lindmark G, Buchwald P, et al. Late leakage after anterior resection: a defunctioning stoma alters the clinical course of anastomotic leakage. Colorectal Dis. 2018;20(2):150-9. https://doi. org/10.1111/codi.13914.

24. Lim SB, Yu CS, Kim CW, Yoon YS, Park IJ, Kim JC. Late anastomotic leakage after low anterior resection in rectal cancer patients: clinical characteristics and predisposing factors. Colorectal Dis. 2016;18(4):0135-40. https://doi. org/10.1111/codi.13300.

25. Yang SY, Han YD, Cho MS, Hur H, Min BS, Lee KY, et al. Late anastomotic leakage after anal sphincter saving surgery for rectal cancer: is it different from early anastomotic leakage? Int I Colorectal Dis. 2020;35(7):1321-30. https://doi.org/10.1007/s00384-020-03608-9 Epub 2020 May 5. PMID: 32372379

26. Sparreboom CL, van Groningen JT, Lingsma HF, Wouters MWJM, Menon AG, Kleinrensink GJ, et al. Different risk factors for early and late colorectal anastomotic leakage in a nationwide audit. Dis Colon Rectum. 2018;61(11): 1258-66. https://doi.org/10.1097/DCR.0000000000001202.

27. Borstlap WAA, Westerduin E, Aukema TS, Bemelman WA, Tanis PJ. Dutch Snapshot Research Group. Anastomotic leakage and chronic presacral sinus formation after low anterior resection. Results from a large cross-sectional study. Ann Surg. 2017;266(5):870-7. https://doi.org/10.1097/SLA. 0000000000002429

28. Extermann M. Interaction between comorbidity and cancer. Cancer Control. 2007;14(1):13-22. https://doi.org/10.1177/107327480701400103.

29. Sarfati $D$, Koczwara $B$, Jackson $C$. The impact of comorbidity on cancer and its treatment. CA Cancer J Clin. 2016;66(4):337-50. https://doi.org/10.3322/ caac.21342.

30. Brown JC, Zhang S, Ou FS, Venook AP, Niedzwiecki D, Lenz HJ, et al, Diabetes and clinical outcome in patients with metastatic colorectal cancer: CALGB 80405 (Alliance). JNCI Cancer Spectr. 2019:4(1):pkz 078. https://doi. org/10.1093/jncics/pkz078.

31. Yamano T, Yamauchi S, Kimura K, Babaya A, Hamanaka M, Kobayashi M et al. Influence of age and comorbidity on prognosis and application of adjuvant chemotherapy in elderly Japanese patients with colorectal cancer: A retrospective multicentre study. Eur J Cancer. 2017;81:90-101. https://doi. org/10.1016/.j.jca.2017.05.024.

32. Giesen LJX, Borstlap WAA, Bemelman WA, Tanis PJ, Verhoef C, Olthof PB; DUTCH SNAPSHOT RESEARCH GROUP. Effect of understaging on local recurrence of rectal cancer. J Surg Oncol. 2020;122(6):1179-1186. doi: https:// doi.org/10.1002/jso.26111. Epub 2020 Jul 11. PMID: 32654177; PMCID: PMC7689834.

33. Lai IL, You JF, Chern YJ, Tsai WS, Chiang JM, Hsieh PS, et al. The risk factors of local recurrence and distant metastasis on $\mathrm{pT} 1 / \mathrm{T} 2 \mathrm{NO}$ mid-low rectal cancer after total mesorectal excision. World J Surg Oncol. 2021 Apr 13; 19(1):116. https://doi.org/10.1186/s12957-021-02223-4.

34. Fajardo LF. Effects of ionizing radiation on lymph nodes. Front Radiat Ther Oncol. 1994;28:37-45. https://doi.org/10.1159/000423371.

35. Baxter NN, Morris AM, Rothenberger DA, Tepper JE. Impact of preoperative radiation for rectal cancer on subsequent lymph node evaluation: a population-based analysis. Int J Radiation Oncology Biol Phys. 2005;61(2): 426-31. https://doi.org/10.1016/j.jirobp.2004.06.259.

36. Akiyoshi T, Tanaka N, Kiyotani K, Gotoh O, Yamamoto N, Oba K, et al. Immunogenomic profiles associated with response to neoadjuvant chemoradiotherapy in patients with rectal cancer. Br J Surg. 2019;106(10): 1381-92. https://doi.org/10.1002/bjs.11179.

37. Parsons HM, Tuttle TM, Kuntz KM, Begun JW, McGovern PM, Virnig BA. Association between lymph node evaluation for colon cancer and node positivity over the past 20 years. JAMA. 2011;306(10):1089-97. https://doi org/10.1001/jama.2011.1285.

38. van Erning FN, Crolla RM, Rutten HJ, Beerepoot LV, van Krieken JH, Lemmens VE. No change in lymph node positivity rate despite increased lymph node yield and improved survival in colon cancer. Eur J Cancer. 2014;50(18):3221-9. https://doi.org/10.1016/j.ejca.2014.10.011.

39. Chen $N$, Sun $\Pi$, Li ZW, Yao YF, Wang L, Wu AW. Fat clearance and conventional fixation identified ypNo rectal cancers following intermediate neoadjuvant radiotherapy have similar long-term outcomes. World J Gastrointest Oncol. 2019;11(10):877-86. https://doi. org/10.4251/wjgo.v11.i10.877.
40. Tsai CJ, Crane CH, Skibber JM, Rodriguez-Bigas MA, Chang GJ, Feig BW, et al. Number of lymph nodes examined and prognosis among pathologically lymph node-negative patients after preoperative chemoradiation therapy for rectal adenocarcinoma. Cancer. 2011;117(16): 3713-22. https://doi.org/10.1002/cncr.25973.

41. Beresford M, Glynne-Jones R, Richman P, Makris A, Mawdsley S, Stott D, et al. The reliability of lymph-node staging in rectal cancer after preoperative radiochemotherapy. Clin Oncol (R Coll Radiol). 2005;17(6):44855. https://doi.org/10.1016/j.clon.2005.05.007.

42. Raoof M, Nelson RA, Nfonsam VN, Warneke J, Krouse RS. Prognostic significance of lymph node yield in ypNO rectal cancer. Br J Surg. 2016; 103(12):1731-7. https://doi.org/10.1002/bjs. 10218.

43. Xu Z, Berho ME, Becerra AZ, Aquina CT, Hensley BJ, Arsalanizadeh R, et al. Lymph node yield is an independent predictor of survival in rectal cancer regardless of receipt of neoadjuvant therapy. J Clin Pathol. 2017;70(7):58492. https://doi.org/10.1136/jclinpath-2016-203995.

44. Kim WR, Han YD, Cho MS, Hur H, Min BS, Lee KY, et al. Oncologic Impact of Fewer Than 12 Lymph Nodes in Patients Who Underwent Neoadjuvant Chemoradiation Followed by Total Mesorectal Excision for Locally Advanced Rectal Cancer. Medicine (Baltimore). 2015;94(28):e1133. https://doi.org/10.1 097/MD.0000000000001133.

45. Degiuli M, Arolfo S, Evangelista A, Lorenzon L, Reddavid R, Staudacher C, et al. Number of lymph nodes assessed has no prognostic impact in nodenegative rectal cancers after neoadjuvant therapy. Results of the "Italian Society of Surgical Oncology (S.I.C.O.) Colorectal Cancer Network" (SICOCCN) multicentre collaborative study. Eur J Surg Oncol. 2018;44(8):1233-40. https://doi.org/10.1016/j.ejso.2018.04.007.

46. Gill A, Brunson A, Lara P Jr, Khatri V, Semrad TJ. Implications of lymph node retrieval in locoregional rectal cancer treated with chemoradiotherapy: A California Cancer Registry study. Eur J Surg Oncol. 2015;41(5):647-52. https://doi.org/10.1016/j.ejso.2015.01.037.

\section{Publisher's Note}

Springer Nature remains neutral with regard to jurisdictional claims in published maps and institutional affiliations.

\section{Ready to submit your research? Choose BMC and benefit from:}

- fast, convenient online submission

- thorough peer review by experienced researchers in your field

- rapid publication on acceptance

- support for research data, including large and complex data types

- gold Open Access which fosters wider collaboration and increased citations

- maximum visibility for your research: over $100 \mathrm{M}$ website views per year

At $\mathrm{BMC}$, research is always in progress.

Learn more biomedcentral.com/submissions 